\title{
Inventários e Testamentos como documentos linguísticos
}

Célia Maria Moraes de Castilho*

RESUMO: O objetivo deste artigo é apresentar uma categorização sócio-histórica dos autores dos Inventários e Testamentos, escritos em São Paulo nos séc. XVI e XVII. Juntamente com as Atas da Câmara da Vila de São Paulo, são estes os documentos públicos mais antigos da cidade. Para atingir esse objetivo, dividi o trabalho em três partes: (i) notas para a história social de São Paulo em seus primeiros séculos, (ii) o português europeu médio e o protocaipira, (iii) os Inventários e Testamentos como documentos linguísticos. Enumero num anexo os escrivães portugueses, paulistas e estrangeiros autores desses documentos, objetivando facilitar sua utilização. Nas Conclusões, estudo a distribuição percentual dos autores de Inventários e Testamentos de acordo com sua origem, e avanço algumas hipóteses sobre a mudança linguística do Português Paulista com base nesses dados.

Palavras-chave: Linguística Histórica, História do português brasileiro de São Paulo, Inventários e Testamentos como documentos linguísticos, Perfil sociolinguístico dos escrivães portugueses, paulistanos e parnaibanos.

ABSTRACT: The aim of this text is to offer a socio-historical categorization of the authors of the text of the Inventarios e Testamentos (I\&Ts), written in São Paulo in the 16th and 17th centuries. Together with the Atas da Camara da Vila de São Paulo, the I\&Ts are the oldest public written documents of the city of São Paulo. To achieve this aim, the text has been divided into three sections: (i) notes on the social history of the first centuries of Sao Paulo, (ii) Middle European Portuguese and the grammar of Protocaipira, (iii) the I\&Ts as linguistic documents. The appendix lists the Portuguese, São Paulo native and foreign authors of the I\&Ts provided to ease the use of these documents for research. In the conclusion I study the distribution of the authors of the I\&Ts according to their origin, with a proposal about linguistic change in the Portuguese language used in São Paulo, based on this data.

Keywords: Historical Linguistics, History of Brazilian Portuguese in São Paulo, I\&Ts as linguistic documents, sociolinguistic characterization of Portuguese, Paulistano and Parnaibano authors of I\&Ts.

* Pós-doutoranda, DLCV / USP, sob a supervisão da Profa. Dra. Marilza de Oliveira. Bolsa Fapesp 06/56510-3. 


\section{Paulo Bomfim-Rosa de Espanha}

Quando Castro Alves escreveu: "Tenho saudades... ai de ti! São Paulo, rosa de Espanha no hibernal friul" pressentia a influência espanhola em hábitos e temperamento dos habitantes "do país do sul". Sua geração caminhou pela Paulicéia, sob mantilhas e capas espanholas, entre os Cristos ensanguentados das igrejas e as corridas de touros que aconteciam no Largo dos Curros, futura Praça da República.

Nos primeiros tempos de Piratininga, reza a tradição, que "quien no es Bueno es malo".

No século XVI, duas esquadras trazem para São Vicente marcos civilizadores. A de Martim Afonso de Sousa e seus pioneiros embarcados no Tejo, e a de Diogo Flores de Valdés, com os primeiros povoadores castelhanos.

A bandeira, na disciplina e na organização, é portuguesa; e espanhola no toque desassombrado de conquista. Nela, o sebastianismo se transfigura em alumbramentos do Eldorado.

Sob o gibão do bandeirante refulge a couraça do adelantado.

A tropa que ruma para o desconhecido é um arquipélago de destinos contraditórios irmanados no mesmo sonho de conquista.

O paulista antigo, é um don juan de horizontes, enamorado de causas impossiveis, das yaras que aguardam seus guerreiros no fundo de lagoas douradas. Na essência de cada mameluco bá sempre a demanda de "algo de nuevo a se mirar". Nos albores piratininganos, a presença espanhola é uma constante. Bartolomeu Bueno da Ribeira é sevilhano, Jusepe de Camargo nasce em Castela, D. Simão de Toledo Piza dá ao filho o sobrenome Castelhano. Balthazar de Godoy chega no reinado de Felipe II, e os Martins Bonilha vêm com Diogo Flores de Valdés. Os Saavedras são originários de Castela, D. Diogo de Lara é de Zamora, e Bernardo de Quadros, provedor e administrador das minas em 1599, procede de Sevilha. Enquanto Martim Rodrigues Tenório de Aguilar leva ao Paraubava a inquietação andalusa, D. Francisco de Lemos traz para São Paulo o brasão de Castela.

A aclamação de Amador Bueno é tentativa de golpe de estado espanhol em terras do rei de Portugal. Seus signatários, inconformados com a ascensão da Casa de Bragança, ostentam origens espanholas. São os irmãos Rendón, da Ciudad de Coria, D. Francisco de Lemos, de Orense, Gabriel Ponce de Leon, da Ciudad Real de Guaira, Bartolomen de Torales, da Vila Rica situada no Paraguai, de onde chegam também, André de Zuñega, D. João de Espinola Gusmán e outros militares. Todos ocupando seus espaços em Piratininga, através de casamentos com as filhas de potentados da terra.

No seiscentismo, a guerra entre Pires e Camargos traz no bojo algo de Aljubarrota. Os Pires, visceralmente lusitanos, contra os Camargos, de 
rompantes castelhanos. O duelo ocorrido no Largo da Sé entre Pedro Taques e Fernão de Camargo, alcunhado "El tigre", foi combate onde Portugal é apunhalado pela Espanba.

Nos séculos XVII e XVIII, a argamassa formadora do cerne das bandeiras é composta de portugueses, espanhóis, mamelucos e indios. Sem essa mescla fascinante de etnias e temperamentos, as bandeiras saídas de São Paulo não teriam ousado plantar, na rosa dos ventos do sertão, seus pavilhões de conquista.

Os jesuitas aqui chegados, trazem sob as sotainas o elã combativo de Ignácio de Loyola, fidalgo que transformou as feridas recebidas em Pamplona nos exercicios espirituais que regeriam a milicia que combate pela conquista dos céus. Em Anchieta, a formação coimbrã luta com raizes canarinas.

O peregrino do êxtase é tipicamente espanhol: Santa Teresa e San Juan de la Cruzpertencem ao universo de El Greco.

Ao proclamar a independência do Brasil, o temperamento arrebatado de Carlota Joaquina sobrepuja, em D. Pedro, o bom senso do pai. $O$ jovem imperador retoma o tema da cavalaria desaparecido em Alcácer Kibir, ressuscitando, na pacata Casa de Bragança, o heroísmo das dinastias de Borgonha e Avis.

D. Pedro nasce e morre no Palácio de Queluz, em aposento cercado das proezas de um fidalgo manchego. Seu temperamento irá oscilar entre o delírio quixotesco materno e o equilíbrio sanchopanseano do pai.

O império brasileiro surge do gesto-gesta do derradeiro cavaleiro andante e morre na praia burguesa da república. Nele, o sangue Camargo, de Feijó, dá um toque de inconformismo e rebeldia.

Nos Lusíadas, a epopéia é planejada; no Quixote, o plano se dilui na aventura.

No sertanismo, a conquista sulina fala o português com Manuel Preto e Raposo Tavares; mas o delírio das minas de ouro tem o sotaque castelhano de Buenos, Laras e Tenórios de Aguilar.

Em São Paulo, extensão de Portugal, "jardim da Europa a beira mar plantado", a rosa de Espanha floresceu com os espinhos das conquistas bandeirantes e o perfume das serenatas estudantis. 


\section{Apresentação}

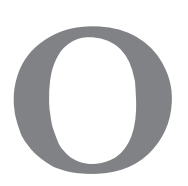

presente texto tem os seguintes objetivos: (1) reunir informações de interesse para o conhecimento da história social de São Paulo em seus primeiros tempos - seção 1; (2) mostrar a conveniência de emparelhar as pesquisas sobre a mudança gramatical do português paulista dos primeiros tempos com as pesquisas sobre o português europeu médio - seção 2; (3) caracterizar os Inventários e Testamentos, doravante I\&Ts, como documentos de interesse para a história linguística do português brasileiro de São Paulo em seus primeiros tempos - seção 3.

Para facilitar os pesquisadores interessados na utilização deste tipo de documento, apresento no Anexo o perfil sociolinguístico de seus autores. Esse perfil fornecerá, igualmente, uma perspectiva sobre a sociedade paulista nos dois primeiros séculos de sua organização.

Por decisão tomada no interior do Projeto de História do Português Paulista, o Prof. Dr. Sílvio Toledo de Almeida se encarregará da edição filológica dos I\&Ts dos séculos XVI e XVII mais representativos, tanto quanto as Atas da Câmara.

1. Preparando a história social do Português de São Paulo nos séculos XVI e XVII.

Nesta seção, abordarei rapidamente os seguintes tópicos: (1) Portugal antes das descobertas, (2) estrutura da sociedade portuguesa no séc. XVI, (3) São Vicente e São Paulo: contactos linguísticos nos sécs. XVI e XVII.

1.1 Portugal antes das descobertas

A Europa Ocidental havia passado por um longo período de desarticulação política e de descentralização, causadas pelo desaparecimento do Império Romano e pelo advento das invasões germânicas. Por volta dos secs. XII-XIII, o continente começa a se reorganizar, expandindo a agricultura, e consequentemente o comércio. Com o aumento dos campos cultivados há excesso de alimentos, que passam a ser trocados entre os povoados, estabelecendo-se assim, um incipiente comércio local. As cidades crescem, a categoria de artesãos aumenta e a se diversifica. Alguns países definem suas fronteiras, e passam a dispor de uma organização política centralizada e de uma burocracia. Países como Portugal e Espanha, através da Reconquista, conseguem retomar territórios que estavam em poder dos mouros havia pelo menos 700 anos. Definem-se as fronteiras nacionais de Portugal, uma das mais antigas da Europa. 
O séc. XIV foi um século de escassez de chuvas e muita inquietação por parte das pessoas, o que levou a Europa a um período de estagnação: revoltas de camponeses explorados contra senhores exploradores, guerras entre os nobres, fome por falta de alimentos, e o pior, várias epidemias como a peste negra, que matou quase a metade da população europeia, deixando os campos despovoados, assim forçando as pessoas a buscar ajuda nas vilas ou cidades. Para vencer essa estagnação era preciso voltar-se novamente para a agricultura, ativar o comércio marítimo e arrumar mão de obra: Fausto (1994). Foi assim que, já no séc. XV, escravos africanos foram trazidos para Portugal: Saunders (1982 / 1994).

Portugal passou quase incólume por esse século tumultuado, dadas as seguintes razões: (i) o território já estava quase todo unificado; (ii) a monarquia, depois de alguns tropeços, estava consolidada, reinando D. João I, filho bastardo de Pedro I; (iii) sendo um país marítimo, conhecia bem as correntes marítimas e fazia viagens há muito tempo; (iv) os portugueses comerciavam com os árabes do Mediterrâneo, utilizando a moeda como meio de pagamento no comércio, no lugar de troca com outras mercadorias, o famoso escambo; (v) as técnicas de marear foram renovadas, de que resultou um tipo especial de navio, a caravela, embarcação leve e veloz: Fausto (1994).

Com a subida do novo rei, D. João I, Portugal se encontrou num dilema: o rei anterior governava do norte do país, contando com uma sociedade e língua arcaizantes. Com o novo rei, a capital do país passou a ser Lisboa, com uma sociedade e língua mais modernas, havendo ainda por resolver o problema dos moçárabes e sua língua. A sociedade e a língua passavam por um período crítico. Foi essa a língua portuguesa trazida ao Brasil.

O séc. XV foi uma época de grandes expansões, em que ocorreu uma mudança radical de ideias e o surgimento de um mundo novo. Iniciava-se o Renascimento e o Humanismo. Antes disso, Portugal dispunha, como os outros países europeus, de uma hierarquia social rígida e imutável. No topo da pirâmide, o rei, em seguida, os clérigos, divididos em alto e baixo clero, os nobres divididos em nobres cortesãos e nobres rurais, por último, o povo, com três níveis: burgueses, artesãos e camponeses, compondo um terço da população. A ninguém era permitido mudar de classe social e a sociedade era desigual: Caldeira (2006), Wehling (1994). Quando a dinastia de Avis subiu ao trono, foram trazidos os melhores mestres da Europa, para educar seus filhos do rei e a elite. Portugal entrava, assim, na era moderna, mas o povo em geral continuava analfabeto. Com essas mudanças todas veio a alteração na estrutu- 
ra do poder, que se tornou centralizado em torno de um rei, auxiliado por funcionários públicos civis e militares. "Assim nascem os quadros administrativos, os experts e a burocracia de Estado": Lopez e Mota (2008), Wehling (1994). O reinado do absolutismo teve sua estreia.

Ainda no século XV, Portugal e Castela entraram em conflito por causa das conquistas marítimas feitas e por fazer, objetivando estabelecer quem ficaria com o quê. Para encaminhar uma solução, o Papa propôs o Tratado de Tordesilhas, que dividia o mundo americano em duas partes, de fronteiras precárias e flutuantes, mas que de todo modo estabelecia as fronteiras das possessões dois países no Novo Mundo.

\subsection{A sociedade portuguesa no séc. XVI}

Há muito tempo Portugal contava com uma expressiva população judia. De uma população de 1.200 .000 habitantes, 190.000 eram judeus: Wiznitzer (1960/1966). Eles ocupavam altos cargos, eram ricos e mercantilistas. Sobretudo, tinham um cuidado muito grande em alfabetizar seus filhos. Todos eram alfabetizados. Nem com as novas ondas de mudança bafejando Portugal a educação e o ensino foram afetadas. Somente as elites tinham acesso à educação, e mesmo assim de forma muito precária. As classes mais pobres continuaram analfabetas, labutando nos campos, mantendo-se o esquema do período medieval. O rei D. Manuel, tendo uma frota marítima incomparável para a época, deu início às grandes expedições e consequentes descobertas das rotas que levavam à África, Ásia e Índia, em busca de especiarias, metais e escravos. Em todos esses lugares precisava haver um corpo administrativo, para garantir a posse do lugar e manter o estado em funcionamento. Isso trouxe um problema muito sério, pois não havia gente preparada e não analfabeta. Aqui entraram os judeus, inclusive no Brasil: Salvador $(1976,1978)$.

Ao subindo ao trono, D. João III, o Piedoso, encontrou um país com as finanças abaladas. Como precisava de muito dinheiro para manter o Império, resolveu instaurar a Inquisição no país, para apropriar-se dos bens dos judeus. Atingidos em cheio, os judeus migraram para a América recém-descoberta, replicando suas atividades na terra nova.

A educação não ocupava os maiores interesses de Portugal, distinguindo-se da Espanha. Os espanhóis construíram universidades no Novo Mundo, em que estudaram padres paulistas que atuavam em São Paulo. A política cultural portuguesa resumia-se a impedir a circulação da informação. 
Com seus colégios, os jesuítas atenuaram esse quadro, cujo maior objetivo, entretanto, era o da doutrinação católica.

A Inquisição empurrou a atividade mercantilista desenvolvida pelos judeus para as Capitanias do Norte (sobretudo Pernambuco) e para as Capitanias do Sul (Espírito Santo, Rio de Janeiro e São Paulo). Por injunções religiosas, como se sabe, os judeus eram alfabetizados, e com isso eles desempenharam um papel interessante no desenvolvimento da variedade escrita culta do português Paulista. Muitos deles viriam a tornar-se redatores dos I\&Ts aqui estudados.

1.3 São Vicente e São Paulo: primeiros contactos linguísticos

Entre 1501-1532, o rei português mandou algumas expedições para impedir o contrabando e mandou construir algumas feitorias, para que ele próprio pudesse explorá-las. Nessas feitorias ficavam alguns homens para cortar as árvores e deixar tudo pronto para o embarque quando as naus chegassem. Foram mandadas expedições, tanto portuguesas como castelhanas, que chegaram até o rio da Prata, área que começava a ser conhecida como região do Ouro e da Prata. Dos navios que haviam passado ao longo desses anos, permaneceram na América muitos homens, dos quais não se sabe a procedência. Eram náufragos, degredados ou desertores.

Dentre estes, os que estavam no litoral paulista há já algum tempo tinham dividido a região que ia de São Vicente até o rio da Prata em três partes: (i) São Vicente, em que moravam João Ramalho, Antônio Rodrigues e Diogo de Braga, todos portugueses, (ii) Cananeia, com seu "bacharel de Cananeia", Gonçalo da Costa, e mais Henrique Montes, Melchior Ramires, Aleixo Garcia, Francisco Pacheco e, (iii) Iguape, em que viviam alguns castelhanos.

Entrando em contato com grupos tupis e guaranis, esses primeiros habitantes aprenderam suas línguas, se casaram com índias e tiveram filhos mestiços. Eles conheciam muito bem todos aqueles sertões e sabiam de lendas que os índios contavam sobre o império do Rei Branco. A notícia correu o mundo da época. Tornava-se cada vez mais conhecida a região do Ouro e da Prata, que ia de São Vicente até o rio de Solis, ou da Prata. Vários homens tentaram ir a esse região imaginária, mas eram barrados pelas águas furiosas do rio da Prata.

Em 1531, saiu uma expedição de Portugal, comandada por Martim Afonso de Sousa, na qual também vinha seu irmão Pero Lopes de Sousa, com 
o propósito de descobrir metais preciosos e povoar algumas regiões do Brasil. Em 1534, chegou a Sevilha uma nau espanhola comandada por Fernando Pizarro trazendo muito ouro e prata. Ele havia entrado pelo México e descoberto índios que usavam muitos desses metais e conheciam as minas. Em 1535, aportou no rio da Prata Pedro Mendoza, comandante de tropas reais, com uma frota de 14 navios e 2.700 pessoas, com o objetivo de encontrar prata. Depois de muitas lutas com os índios locais, de muitas mortes e de muita fome, só sobraram 560 pessoas. Pedro Mendoza e um grupo de seus homens resolveram voltar para a Espanha, mas ele morreu a bordo de sua nave. O capitão Juan de Ayolas e seu grupo subiu o rio Paraná, tendo chegado à foz do rio Paraguai sem comida, e só com 300 pessoas. Conseguiram chegar à região dos carijós ou guaranis. Como esses índios possuíam muitas plantações, os espanhois conseguiram matar a fome. Ambas as partes acharam que seria interessante fazer um acordo mútuo de defesa. Como os carijós possuíam terras muito boas para o cultivo, viviam sempre sendo atacados por tribos nômades que queriam roubar a comida. Com os espanhóis se ajuntando com mulheres índias, graças ao instituto do cunhadismo, eles passaram a defender as lavouras índias. Assim, em 1537 foi fundada a cidade de Assunção, no Paraguai: Caldeira (2006).

A vila de São Vicente já existia há muito tempo e havia ganho esse nome por volta de 1501. Nessa mesma época havia ali várias casas, habitadas por portugueses como João Ramalho, Antônio Rodrigues e Diogo de Braga, casados com índias, tendo filhos mamelucos. O objetivo principal da expedição de Martim Afonso foi a de procurar metais preciosos, sabendo que a região de São Vicente era um dos caminhos para se chegar à região das pratas, ao percorrer aquele caminho indígena chamado Peaberu: Toledo (2003). Mas ele veio também para iniciar o povoamento da região.

Com Martim Afonso, São Vicente recebeu elementos que faziam dela uma vila, ou seja, os homens ganharam terra para cultivar, oficiais foram nomeados, instalando-se a justiça: Toledo (2003)

A esse quadro, agreguem-se os contatos linguísticos de lusofalantes com os povos indígenas do Brasil, e posteriormente, com os africanos.

Nos primeiros tempos da colonização, os portugueses se indianizaram, incorporando técnicas de construção de malocas, hábitos alimentares e falando a língua geral. De 1580 a 1640 unem-se as coroas, de que resultou a União Ibérica. Portugueses e espanhóis desconhecem as fronteiras geográfica, pro- 
movendo-se amplas trocas de produtos no triângulo formado por São Paulo - Buenos Aires - Potosi.

A vila de São Paulo era um confuso conjunto de aldeias, sempre atacadas por indígenas influenciados por europeus. Em 1587, Jerônimo Leitão vem de São Vicente, organiza uma milícia, que neutraliza os ataque indígenas, construindo muros precários à volta do burgo. Em 1599, chega a São Paulo o $7^{\circ}$ Governador Geral do Brasil, D. Francisco de Sousa, apelidado o "Francisco das Manhas", à busca de metais preciosos. Ele traz consigo vários secretários, reforçando o número de colonos alfabetizados.

São Paulo expande-se no séc. XVII, surgindo uma burguesia bastante ativa, que tem no Pe. Lourenço CastanhoTaques, o Banqueiro do Sertão, sua figura máxima. Filho de um homem rico, esse Taques expandiu muito sua fortuna, trazendo prata de Potosi, na atual Bolívia: Caldeira (2006).

2. As vésperas brasilianas: o português médio e o protocaipira

Adotei para título desta seção a expressão "Vésperas brasilianas", utilizada por Ivo Castro na denominação do X Seminário do Projeto Caipira (São Paulo, 2009), sob sua coordenação.

$\mathrm{Na}$ seção anterior, apresentei o quadro social aqui encontrado e/ou organizado pelos falantes do português médio. Um dos objetivos do Projeto de História do Português Paulista é identificar e descrever a gramática do protocaipira, que deriva do português médio.

As seguintes perguntas configuram esse objetivo: (1) que modalidade de português foi trazida para São Paulo? (2) como documentar essa modalidade em documentos gerados em São Paulo? (3) por que alterações ele passou em sua nova ecologia? Estas questões são consideradas brevemente nos itens a seguir.

2.1 A gramática do português médio

A pergunta "que modalidade de português foi trazida para o Brasil" aponta para a necessidade de um conhecimento mais acurado do português adquirido pelos colonizadores em seu ambiente familiar, antes de empreenderem a travessia atlântica.

Em trabalho anterior, hipotetizei que é quatrocentista a base do português brasileiro: Moraes de Castilho (2002). Posteriormente, encontrei evidên- 
cias sintáticas em documentos do português arcaico, as quais mostravam que estruturas tais como a construção de tópico, as alterações na classe dos pronomes, a formação do dequeísmo, dadas comumente como criações brasileiras, encontram suas raízes na época imediatamente anterior ao Descobrimento. Postulei que esses fenômenos são desdobramentos do processo de redobramento sintático: Moraes de Castilho (1998/2001, 2004, 2005 a,b).

O redobramento sintático é uma construção fundamentada na relação de interdependência, não muito estudada em nossas gramáticas e em manuais de sintaxe. Vou defini-la assim: uma dada classe $\mathrm{X}$ ocorre juntamente com uma classe $\mathrm{Y}$, de tal sorte que ocorrendo $\mathrm{X}$, obrigatoriamente co-ocorrerá $\mathrm{Y}$.

Os constituintes X e Y são integrados por categorias distintas, desde uma classe de palavra até uma construção, sendo que ambas desempenham na maior parte das vezes uma mesma função. Isso significa que nos enunciados redobrados ou correlatos uma dada função é preenchida mais de uma vez, fenômeno que a gramática tradicional rotulou de "anfilogismo". Quer dizer, portanto, que redobramento e correlação representam designações diferentes para um mesmo fenômeno. Neste trabalho, darei preferência ao termo "redobramento", visto abranger uma variedade maior de construções.

O redobramento se manifesta através de recursos gramaticais muito variados, e por isso mesmo nem sempre nos damos conta de que estamos diante de um mesmo fenômeno. Admitirei que as seguintes estruturas manifestam o redobramento sintático, com maior ou menor visibilidade:

(1) $\mathrm{X}=$ construção de tópico / $\mathrm{Y}=$ pronome resumptivo: redobramento por topicalização.

O redobramento por topicalização dá origem às Construções de tópico (CTs), bastante estudadas no Brasil a partir dos anos 80. Uma CT decorre do movimento do sintagma nominal (SN) ou do sintagma preposicionado (SP) para a esquerda, retomando-o por um clítico pessoal ou por uma categoria vazia.

As diferentes funções do SN / SP nos levam às CTs de sujeito, de objeto direto, de objeto indireto e de adjunto, exemplificadas no português arcaico:

(1) Redobramento da CT sujeito

a) [XIV CGE2 17: 15] Mas o grande Hercolles (...) este foy muy grãde, muy ligeiro, muy valente mais que outro homem. 
(2) Redobramento de CT objeto direto

a) [XVLM 28:18] E esto nom $\mathbf{0}$ queremos mais dizer, porque todos sabem, que he assi como nos dizemos.

(3) Redobramento de CT objeto indireto

a) $\quad[X V V S$ 50:24]E a a lma estando em tanto prazer disse-lhe o angeo...

b) $\quad X V V P A 1$ 95:47Sam Filipo, estando em Samaria (...) disse-lhe 0 angio de Nostro Senhor...

(4) Redobramento de CT oblíquo e adjunto

a) XIV LLD 122:22] Eesta dona Violante Sanches casou com ela o conde dom Martim Gil de Portugal, [...]

(2) $\mathrm{X}=$ pronome pessoal, possessivo, demonstrativo $/ \mathrm{Y}=$ sintagma preposicionado: redobramento de clíticos pessoais e de outros pronomes.

O redobramento dos clíticos se constitui no campo mais versado das pesquisas sintáticas. Esse processo é muito importante, pois dele resultaram alterações no quadro dos pronomes, como se pode constatar pelos exemplos:

(5) Duplicação de pronomes pessoais clíticos, pronomes possessivos e demonstrativos

a) [XIII SG 325:8][...] e entom aguilharom mais de $X$ a Paramades e matorom-lhe o cavalo e chagarom-no a el de muitas chagas. [duplicação do clítico acusativo]

b) [XV CDP 276:25][...] se este be o seu filho Joane de que me a mim algũuas vezes fallarom. [duplicação do clítico dativo]

c) [XIII CSM1 LXI:8] Tan grand' [é] a sa merçee | da Virgen $e$ sa bondade, / que sequer nas beschas mudas | demostra sa piadade. [duplicação do possessivo]

d) [XIII CSM1 XXXII:4] Tanto, se Deus me perdon, / son da Virgen connoçudas / sas merçees, que quinnon / queren end' as bestias mudas. //

e) [XIII DSG 9:35] E o monge Libertino outrossi deitou-se ante os pees de seu abade e disse-lhi que aquele mal que el recebera non for a per sa crueza do a bade, mais for a persa culpa del mesmo.

f) [XIII FR 129:6] [...], assy a maldade dos que sõ endurados e perfyosos en fazerlhys mal non tha poden toller senõ per grauer $p^{1 / 2}$, , as, ca $\mathbf{0}$ diz a Escriptura que o sandeu en sandice guisesse de seer cordo que non suffra pea. [duplicação do demonstrativo neutro]

(3) $\mathrm{X}=$ pronome circunstancial locativo, temporal $/ \mathrm{Y}=\mathrm{SP}$ : redobramento de clíticos locativos e temporais. 
Também os clíticos locativos e temporais deram origem a várias alterações na gramática do português arcaico, com repercussões no português brasileiro:

(6) Locativos e temporais redobrados

a) [XIII HGP 77:20] [...] e que dedes ende $\tilde{\imath}$ cada ano áó moesteyro de Chouzã per seu maordomo meadade de vino no lagar e meadade de todo pam que $\mathbf{y}$ lauorardes $\mathbf{n a}$ eyra.

b) [XIII FR 167:10] Outrosy dementres que for en corte del rey, des aquel dya que se en partir de sa casa por todo bun dia seya y seguro (E) el con todas sas cousas, assy comoé subretido, $[\ldots]$

c) [XIV LLCP 138:10] E por esta mortiindade, que I foi tamanha que as pedras e o campo foi todo vermelho, poserom-lhe nome ao campo o campo de Arguriega, que tanto quer dizer por seu linguagem de vasconç, como pedras vermelhas pelo nosso; e hoje em este dia assi ha nome. [duplicação do circunstancial de tempo]

d) [XVI BD 21:2] [...] que nom bá I alguñ que leixar casas e irmaãos ou padre ou madre ou herdades, que nom receba cem-tanto agora em este tempo, e depois haverá vida perdurável. [duplicação do circunstancial de tempo]

(4) $\mathrm{X}=$ advérbio de negação / $\mathrm{Y}=$ advérbio de negação: redobramento da negação.

Deriva desta sintaxe a aparente posposição da negação no português brasileiro, como em sei não. O que tivemos aqui foi, na verdade, a elisão do constituinte $\mathrm{X}$ da negação redobrada:

(7) Advérbio de negação redobrado

1. [XIII SG 123:9] E atendeo tanto que Calogrenac ouve a pior da batalha, ca muito era Lionel ardido e arrizado, e Calogrenac avia ja assi seu elmo metudo em peças e seu scudo e sua loriga que nom atendia ja se morte $\mathbf{n o m}$; e tanto perdera ja do sangue que nom podia ja estar.

2. [XIII SG 125:8] "Ora me dižede o que I faça, irmão", disse Boorz; "en nom posso aqui mais star, mas vos ficade. [...]

3. [XIII SG 129:17] E eu nom posso ja mais star aqui, ca ves aqui Persival, o bem aventurado e gl[o] rioso que te vem aqui buscar ora e veer".

4. [XV VS 39:21] Ay senbor nu? ca te vy senõ agora quando ou / vy tua voz muy saborosa.

5. [XV VS 57:41] E nunca abria a porta / sse nom quando viinha algũ monge por algũa cousa necessaria.

6. [XIII-XIV CA 163:18] Pero faca como quiser', / ca sempre a eu servirei, / e quando a negar poder', / todavia negá-la-ei; / ca eu ¿ por quê ei a dizer / o por que m' ajan de saber / quan gran sandece comecei, // E de que menon á quitar / nulla cousa, se morte non? /

(5) $\mathrm{X}=$ quantificador $/ \mathrm{Y}=$ quantificador: redobramento de quantificadores. 
A flutuação do quantificador todo, objeto de pesquisas no português brasileiro, encontra sua origem no português arcaico, sobretudo na fase do português médio:

(8) Quantificadores redobrados

a) [XVVS 47:29] E o ango rrespondeo aguardemos e veerás a cabo de pouco foy a casa tam escura e quantos estavã em ella todos (se) tornarom tristes.

b) [XVVS 34:31] Oo meu senhor / tudo qua nto queres fazer todo fazes asy nos ceeos co I mo na terra e en no mar e e nos avisos e nõ ha by cou/sa que possa contradizer aa tua võtade e e ty e de ti e por / ty som todalas cousas feytas e sem ty nõ ba by ne / nhũa cousa.

c) [XVVS 47:19] E quantos estavã em aquella casa todos ficavã os joelhos ante aquell rrey e diziã hũu vesso do psalteiro / que diz asy.

d) [XVVS 47:29] E o ango rres / pondeo. Aguardemos e veerás. A cabo de pouco foy / a casa tam escura e quantos estavã em ella todos (se) tor / narom tristes.

e) $\quad$ XVVS 26:8] Nom te avondava a cidade de Eleopolis que em / outro tenpo foy mynha

(6) $\mathrm{X}=$ complementizador $/ \mathrm{Y}=$ complementizador: redobramento de complementizadores.

(9) Repetição do complementizador

a) [XVVS 50:26] Conve?-te que te // tornes ao teu corpo. E contarás todas estas cou / sas que viste. Por tal que o(s) que te virem e esto ouvire? que / tome? exenplo de bem fazer e guardar-sse de mal.

b) [XIV LLCP 220:37] [...], temendo-se de cavalgar, com a fraqueza, o que ele encubria mui bem a todos, pedio-lhes que, se ele desperecesse naquela lide, que ficasse dom Egas Gomez de Sousa em seu logo, que era de boa linhagem e de grande bondades.

c) [XV CA200 47:3] Orapregunto se depois desto se non côfesarse $\mathbf{S e}$ tornam ael aquelles pecados de que Ia he perdoado.

(7) $\mathrm{X}=$ oração $1 / \mathrm{Y}=$ oração 2: redobramento por correlação.

Há vários tipos de orações correlatas. Limito-me às correlatas aditivas e às correlatas consecutivas, ambas derivadas do processo de redobramento sintático.

(10) Correlação aditiva

a) [XIV DSG 4:10] E tan comprida era a vida que fazia que non sola mente d'obras maas e desaguisadas, ma is de palavra sobeja, que non presta nen empeence a nengii, a que chama a Escritura ociosa, se guardava

b) [XIII SG 37:14]E assi como mais maravilhas avirom deste scudo ca doutro, assi averá mais bondade darmas e de santa vida em aquel, que o ha de trazer, ca em outro cavalleiro. 
274 Célia Maria Moraes de Castilho

(11) Correlação consecutiva

a) [XIV DSG 34:28] Ca tan sobejo foi o prazer da carne que ouve que aquelo que fez. con seu marido fezera-o con outro qualquer.

b) [XIV DSG 49:5] E ta nta foi a coita e a door que ende receben que todo o deleito e o prazer que ouvera da molher que o enmiigo ant' os seus olhos apresentara perdeu-o e des ali adeante nunca o ouve.

Aprofundando a análise do redobramento dos clíticos locativos hi e ende, comprovei em outros estudos que daí resultaram (1) a criação das perífrases de estar + gerúndio e estar + infinitivo preposicionado, (2) o desaparecimento do clítico acusativo o, (3) a criação do possessivo dele, que preencheu a casa vazia do possessivo da terceira pessoa, quando teu desapareceu e seu passou a ser reanalisado como possessivo da segunda pessoa, (4) a construção conhecida como "dequeísmo".

\subsection{A gramática do protocaipira}

As afirmações acima tiveram uma inesperada confirmação adicional graças às pesquisas desenvolvidas por Esperança Cardeira, sob a orientação de Ivo Castro, em Portugal.

Cardeira (2005: 275-282) mostra que de 1450 a 1540 caracterizou-se em Portugal o português médio, que se distinguiu fortemente do período anterior e do período clássico, dadas as seguintes características fonológicas e morfológicas (ver também Castro 2008: 149-184):

- Encontros vocálicos: a sequência -eo, -ea

- Sequências nasalizadas em contexto final (convergência em -ão)

- Síncope de $-d$ - no morfema número-pessoal

- Particípios em -udo / -ido

- Plural dos lexemas de singular em -l

- Sistema de possessivos

Vê-se que falta estender o achado de Cardeira ao campo da sintaxe. De todo modo, a pesquisadora demonstrou que a gramática do português desse período representa uma crise profunda que abalou a língua, crise essa a que se correlacionam duas outras crises, já aqui mencionadas: (i) a peste, que matou as pessoas que saíam à rua, de que resultou o extermínio dos pais e a sobrevivência dos avós e de seus netos, desaparecendo a geração intermediária; (ii) o 
surgimento dos Avises, nova dinastia que substituiu os Borgonha e revolucionou a língua literária, através dos escritos da "ínclita geração", designação dada aos filhos de D. João I e Da. Felipa de Lencastre.

Para aprofundar essas perspectivas, realizou-se em São Paulo, de 3 a 7 de agosto de 2009, o X Seminário do Projeto de História do Português Paulista, sob a coordenação do Prof. Dr. Ivo Castro, da Universidade de Lisboa.

Subtitulado Vésperas Brasilianas, o seminário foi dedicado à exploração do estado da língua na segunda metade do séc. XV e inícios do XVI, através do exame de textos da época.

O objetivo maior estava em chamar a atenção dos pesquisadores brasileiros para o português médio, assim denominado por situar-se entre o português arcaico e o português clássico. Conforme já disse, o português médio foi trazido ao Brasil pelos primeiros colonizadores.

Ao término daquele seminário, recomendou-se constituir um grupo de trabalho luso-brasileiro para o exame de questões sintáticas do português médio, com fundamento em documentos escritos em Portugal, de 1450 a 1550, e no Brasil, de 1500 a 1550. A descrição do português médio oferecerá o pano de fundo para a identificação da gramática do protocaipira, visto haver uma relação de contiguidade temporal entre essas duas manifestações. Essa modalidade foi levada a várias partes do Brasil pelo movimento das bandeiras e pelo tropeirismo.

2.3 Os Inventários e Testamentos e a história social do português caipira

Os I\&Ts situam-se entre os primeiros documentos escritos no Brasil. Para sua exploração sistemática, será necessário previamente identificar o perfil sócio-histórico de seus autores.

A História social do português paulista fundamentada na análise desses textos permite identificar os seguintes eixos:

(1) A família portuguesa em São Vicente e em São Paulo: formação da aristocracia. Este eixo compreende os primeiros colonizadores, portugueses em sua maioria, e alguns poucos castelhanos. Eles mantinham contactos regulares com a metrópole e com o Rio de Janeiro, formavam a aristocracia local, e forneceram os primeiros autores dos I\&Ts. A análise de sua linguagem poderá oferecer pistas para a interpretação do dialeto santista, bem distinto do dialeto caipira, tema que não foi incluído neste projeto. 
Muitos desses portugueses são cristãos-novos, o que garante a esse contingente uma grande importância para a história da implantação da língua escrita entre nós.

(2) A família paulista na vila de São Paulo: princípios da globalização. Melhores condições de solo e de segurança levaram-na a migrar do litoral para o planalto, inicialmente para Santo André da Borda do Campo, e depois para São Paulo. A produção agrícola fez desta região o primeiro celeiro nacional, com exportações de farinha da guerra e carne seca para outras áreas do país. Novo movimento migratório teve início em 1580, motivado pelo crescimento demográfico de São Paulo e por rivalidades surgidas no planalto: lembre-se a célebre disputa entre os Pires e os Camargos, que levou estes a se deslocarem para Santana do Parnaíba. O contingente deslocado agora é mais complexo, pois combina portugueses, castelhanos, mamelucos e paulistas de um lado, homens de cabedais e pobretões de outro. Este eixo da formação da sociedade paulista anuncia novos rumos que seriam plenamente desenvolvidos nos séculos por vir. Uma nova leva de autores de I\&Ts vai somar-se à dos anteriores.

(3) A família mameluca na vila de Santana de Parnaíba: formação da burguesia. Com a expansão populacional e o surgimento de novas oportunidades de negócios, surge a burguesia paulista. Os autores dos I\&Ts começam a ser recrutados entre os mamelucos, o primeiro dos quais foi Ascenço Luís Grou.

Esses três eixos permitem distinguir as seguintes categorias de autores de I\&Ts: os portugueses, os paulistas e os não paulistas. Havia cristãos novos como membros dessas categorias, e mamelucos como membros da segunda e da terceira categorias: ver Anexo.

3. Inventários e testamentos como documentos linguísticos

Caracterizo nesta seção os I\&Ts como documentos linguísticos, estudando sua estrutura discursiva.

Como se sabe, os documentos que integram um corpus diacrônico devem ser cuidadosamente localizados no espaço e no tempo, segundo Barbosa (2010), cobrindo ademais diferentes gêneros discursivos, visto que a 
documentação da mudança não ocorre com a mesma nitidez nos diferentes gêneros: Simões/Kewitz (2010).

Nesta seção, estudarei brevemente a estrutura discursiva dos I\&Ts, transcrevendo alguns desses documentos.

3.1. Estrutura discursiva dos Inventários

À primeira vista, um Inventário parece ter uma estrutura caótica, mas é possível identificar suas partes, mesmo constatando-se que elas não ocorrem homogeneamente, o que aponta para a mudança do próprio gênero.

Os Inventários apresentam a seguinte estrutura discursiva:

1. Preâmbulo

2. Rol dos bens e fazenda do falecido / avaliação desses bens

3. Soma e partição dos bens, entre os herdeiros, depois de serem descontadas as dívidas do morto e o pagamento do pessoal administrativo

4. Pregão e arrematação dos bens do falecido

5. Empréstimo do dinheiro dos órfãos

No Quadro 1, identifico a estrutura discursiva dos Inventários que estudei, separando o Inventário feito na vila do Inventário feito no sertão.

Quadro 1 - Estrutura textual de um Inventário

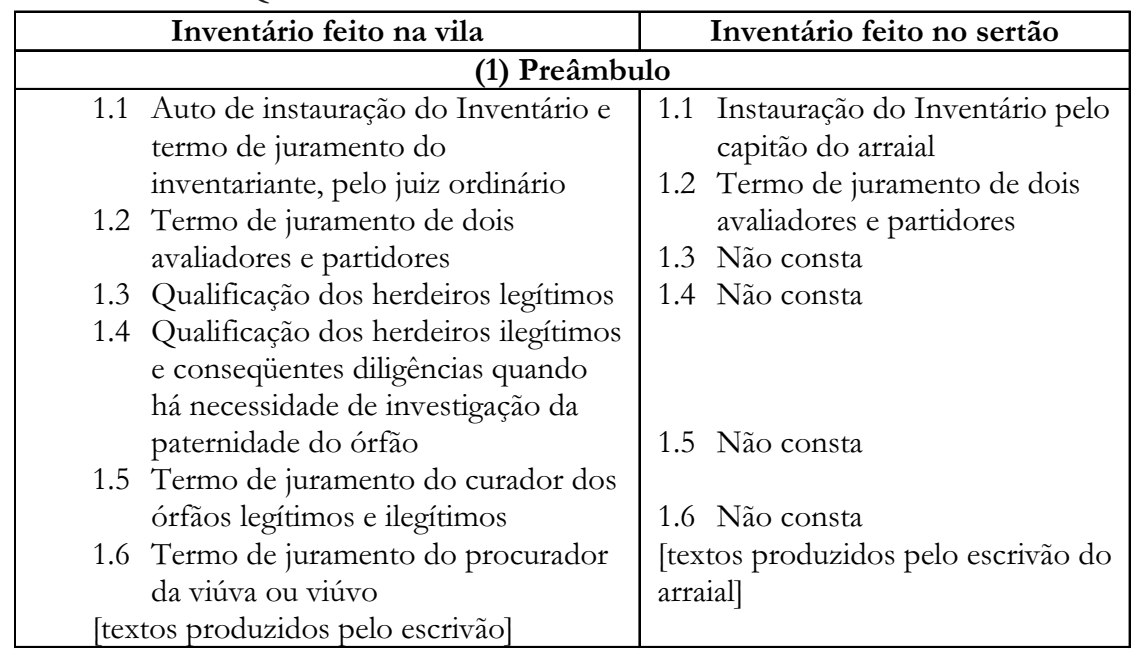




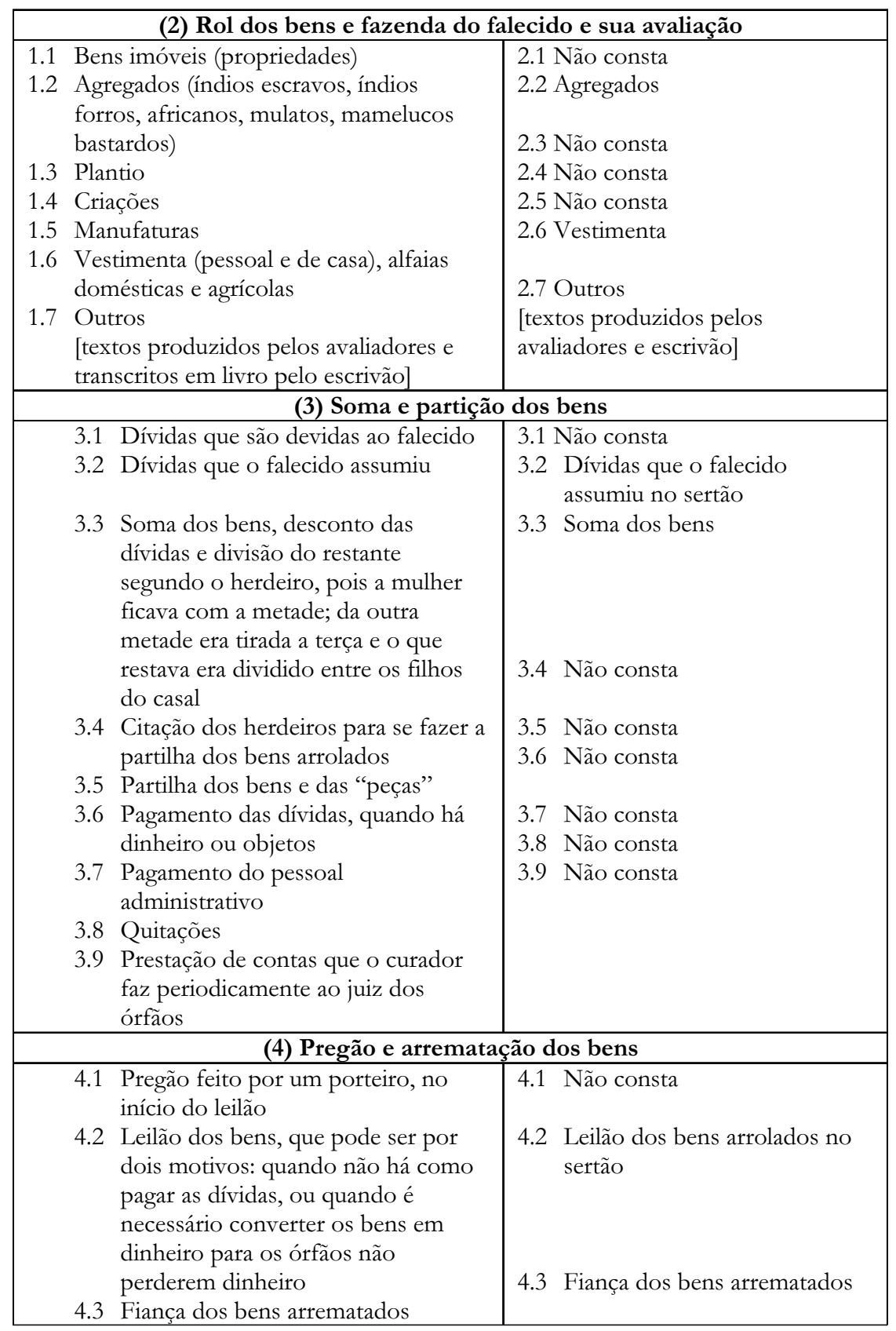


4.4 Pagamento dos bens arrematados com dinheiro de contado, portanto na hora, ou com prazo de três meses até 2 anos, ou fiado, para pagar quando pudesse

4.5 Quitação dos bens arrematados, ou pelo arrematador ou pelo seu fiador

arrematados depois que voltar à vila

4.5 Quitação dos bens arrematados

\section{(5) Dinheiro arrolado dado "a ganho"}

\begin{tabular}{ll|l}
1.1 & Depois de vendidos os bens, o & 5.1 Não consta
\end{tabular} dinheiro arrecadado era emprestado à taxa de $8 \%$ ao ano com prazo de pagamento de um ano;

5.2 Não consta

1.2 Tinha que ser apres entado um fiador abonado, que ficava encarregado de pagar o empréstimo caso o outro não pagas se

Podemos propor a seguinte tipologia dos Inventários:

(i) Aqueles que foram feitos na vila ou no termo ou paragem (= bairros) de uma dada vila; assim, um inventário podia ter sido feito na vila de São Paulo e no termo de Birapoera, termo de Pinheiros, termo do Tatuapé, termo da Nossa Senhora da Penha de França, etc.

(ii) Aqueles que foram feitos no sertão, levam o nome do lugar onde as entradas / bandeiras constituíam o arraial quando iam lutar e prear índios; assim, sertão de Paranaíba, sertão de Paraibuna, sertão e rio de ....

A diferença entre esses dois tipos é muito pequena, mas mesmo assim relevante para o estudo da mudança gramatical. Análises preliminares caracterizadas em Moraes de Castilho (2009 a) apontam para a conveniência, ademais, de levar em conta o local, tanto quanto o escrivão que preparou o documento.

O Inventário paulista mais antigo é conhecido como "o inventário do sapateiro" que data de 1578. Nesse inventário se relata a pouca herança de um jovem sapateiro, talvez português, chamado Damião Simões, que ao morrer deixa sua mulher "prenhe" de seu primeiro filho, que nasce depois da morte do pai, de quem recebe o mesmo nome: 
Inventário do sapateiro $^{1}$

avaliado em tudo avaliado. um tinteiro de diz foi

Uma roupeta de algodão em quatrocentos réis.

Umas ceroulas de algodão brancas foram avaliadas em cento e cincoenta réis.

Tres pares de canos de botas de porco foram postos em seiscentos réis.

Tres pares de canos de botas de porco foram postos em cento e cincoenta réis Tres pares de canos de sapatos de mulher por sollar foram postos em cento e cincoenta réis.

Uma mocinha escrava tamoya.........................pequenos e um .............posto em oitocentos réis.

Declarou elle Balthazar Rodrigues [juiz ordinario nesta dita villa de São Paulo do Campo da capitania de São Vicente] que a viúva anda prenhe... e que não tinha filho nem filha e que o defunto á hora de sua morte lhe dissera que deixava a terça de sua fazenda á dita sua mulher.

3.2 Estrutura discursiva dos Testamentos

Os Testamentos apresentam a seguinte estrutura discursiva:

1. Qualificação do testador e do testamenteiro.

2. Enumeração das missas que serão rezadas por sua alma, especificando-se o pagamento correspondente.

3. Enumeração dos bens.

4. Reconhecimento de dívidas e suas quitações eventuais.

5. Transferência de posse, em que $X$ lega a $Y$ seus bens e fazenda $Z$.

6. Avaliação dos bens a serem transferidos, dando lugar à estrutura $X$ avalia $Z$, em / por $Y$, em que X é o avaliador, Z são os bens, e Y é o valor da fazenda.

7. Fechamento do texto.

O Testamento publicado mais antigo data de 1590, e dele transcrevo algumas partes:

Inventarios e Testamentos. Papeis que pertenceram ao $1^{\circ}$ Cartorio de Orfãos da Capital. São Paulo: Typographia Piratininga, vol. I, 1920, pp. 41-44.

1 Inventarios e Testamentos. Papeis que pertenceram ao $1^{\circ}$ Cartorio de Orfãos da Capital. São Paulo: Typographia Piratininga, vol. I, 1920, p. 4. 
[...] saibam quantos este instrumento e cedula de testamento virem em como eu Gracia Rodrigues mulher de Pero Leme cavalleiro fidalgo em como estando ora muito doente em artigo de morte por não saber o que Nosso Senhor será servido fazer de mim e me levar desta vida presente determinei de mandar fazer esta cedula de testamento [...] e rogo a todas as justiças que mandem cumprir o que aqui deixo porque esta é minha última e derradeira vontade. Primeiramente encommendo minha alma [...] E ao... será o que Pero Leme meu marido quizer mandar e ao mez dirão outra missa resada a honra da paixão de Nosso Senhor Jesus Christo [...] Mando que á confraria de Nosa Senhora da Assumpção darão um cruzado aos mordomos della e umas toalhas the darão de panno de algodão para o altar de Nossa Senhora [...] Mando que do remanescente da minha terça o herdeiro della meu marido Pero Leme como o acima dito e digo que quantoaos cem cruzados que meu pae Gaspar Rodrigues de Moura me prometteu que sendo caso que elle queira herdar na fazenda de meu marido Pero Leme trará os ditos cem cruzados ao monte maior ou sua valia delles e não querendo entrar em tal caso deixo tudo a meu marido o que se achar que é meu porquanto eu não trouxe nada commigo quando com elle casei e porquanto esta é minha última e derradeira vontade pedi e roguei a Paulo de Veres meu compadre que esta cedula fizessed e assignasse e assim o peço a todas as justiças que assim o mandem cumprir e lhe roguei que este fizesse de sua letra. Feito boje cinco de agosto de noventa annos e assigneu eu Paulo de Veres por ella por ser mulher e não saber assignar. Pero de Veres Gracia Rodrigues.

Tanto quanto no caso dos Inventários, ao analisar a mudança gramatical documentada nestes documentos, é importante ter em mente que os segmentos de sua estrutura discursiva atestam diferentemente a mudança havida. Ou seja, alguns segmentos são mais formulaicos, mais conservadores, ao passo que outros segmentos são mais abertos à documentação da língua real de seu tempo.

Conclusões

Quantifico no quadro a seguir os autores dos I\&Ts abaixo relacionados, para ver o que se aprende com isso.

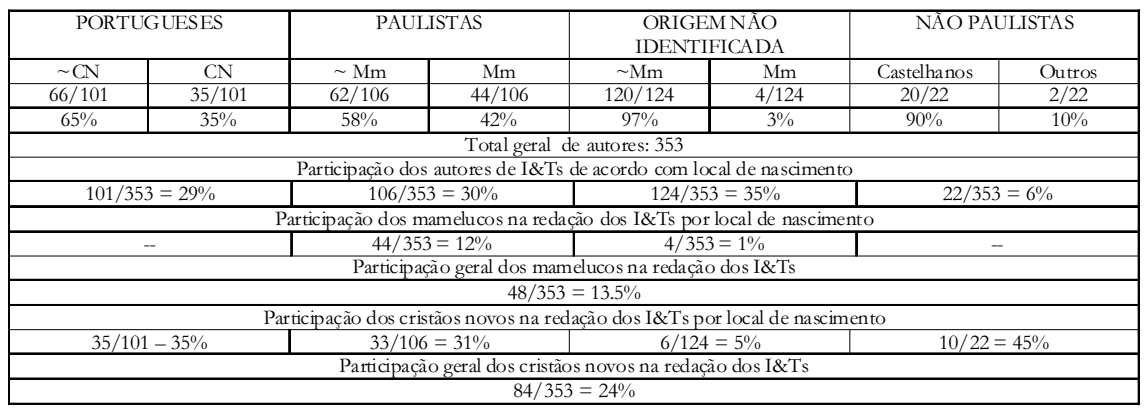

Quadro 2 - Distribuição dos autores de I\&Ts de acordo com seu local de nascimento 
O Quadro 2 mostra uma distribuição equilibrada entre os autores categorizados por seu local de nascimento. A progressiva identificação da origem dos autores da coluna 3 alterará obviamente esses resultados - mas essa será uma tarefa muito árdua, e sem certeza de sucesso.

Por enquanto, estudaremos apenas os documentos produzidos pelos autores reunidos nas colunas 1 e 2 . Aqueles da coluna 4 terão interesse para a história dos contactos linguísticos na Capitania de São Paulo e São Vicente em seus primeiros tempos. Essa área de estudos foi esboçada na seção 1.3 acima.

Chama a atenção a participação de mamelucos e cristãos novos nesse ofício.

Os mamelucos escreveram $13.5 \%$ dos documentos analisados, quase a metade da produção de portugueses e paulistas. Numa análise linguística mais fina, será interessante comparar a linguagem dessas três categorias de autores.

Os cristãos novos tiveram uma presença mais forte nesse ofício, tendo escrito $24 \%$ dos I\&Ts, ou seja, praticamente um quarto dos documentos, o que os aproxima dos autores portugueses e paulistas.

Esse número pode causar surpresa, se considerarmos que poucos portugueses para cá migrados dominavam a escrita, conforme apontamos na seção 1.2 acima. Isto quer dizer que os cristãos novos replicaram na colônia as atividades de estado que desenvolveram na metrópole.

Dadas as peculiaridade da vida desse contingente, sempre ameaçado pelas perseguições, pode-se hipotetizar que eles dispunham de pelo menos duas variedades linguísticas, tanto no velho como no novo mundo: uma linguagem vernácula e uma linguagem veicular.

A linguagem vernácula seria restrita aos indivíduos no trato intrafamiliar. Deveria dispor de um poder referencial menor, dado que seus usuários se conheciam, e partilhavam um conjunto de conhecimentos que dispensava maiores explicitações. Por consequência, o investimento conversacional não dependia de muita elaboração. A língua se tornava mais conservadora.

Já a linguagem veicular seria usada fora do círculo familiar. Como se sabe, os judeus e cristãos novos organizaram círculos comerciais em constante expansão, agregando sempre novos parceiros. Embora partilhassem interesses comuns, esses círculos dependiam de um poder referencial maior, o que os levava a explicitar mais as coisas, em suas conversas. Por consequência, o investimento conversacional era mais intenso. A língua se tornava mais inovadora. 
Se essa hipótese se confirmar, nota-se que o contraste entre o PE do Norte, mais conservador, e o PE do sul, mais inovador, foi replicado de algum modo por este influente contingente humano, com seu contraste entre linguagem familiar conservadora e linguagem veicular inovadora.

$\mathrm{Na}$ continuação destas análises, pretendo separar portugueses do continente (do norte e do sul) e portugueses das ilhas, de forma a não misturar dados de seus textos, que podem apontar para outras tantas peculiaridades linguísticas, atuantes nestas "vésperas brasilianas".

\section{Bibliografia}

BARBOSA, A.G. (2010). Linguística de corpus, Sociolinguística histórica e o lugar dos grupos de fatores externos: o controle espaçogeográfico. Em D. da Hora e C. Rosa Silva (orgs. 2010). Para a História do Português Brasileiro. Abordagens e perspectivas. João Pessoa: Ideia/Editora Universitária, pp. 14-20.

CALDEIRA, J. (2006). O banqueiro do sertão, 2 volumes. São Paulo: Mameluco.

CARDEIRA, E. M. da C.M. (2005). Entre o Português Antigo e o Português Clássico. Lisboa: Imprensa Nacional - Casa da Moeda.

CASTRO, I. (2008). Introdução à História do Português. Lisboa: Edições Colibri.

FAUSTO, B. (1994D/1998). História do Brasil, 6a edição. São Paulo: Editora da Universidade de São Paulo: Fundação do Desenvolvimento da Educação.

FRANCO, F. de A. C. (1989). Dicionário de bandeirantes e sertanistas do Brasil: século XVI, XVII, XVIII. Belo Horizonte: Itatiaia; São Paulo: Editora da Universidade de São Paulo.

INVENTÁRIOS E TESTAMENTOS DA VILA DE SÃO PAULO DO CAMPO DE PIRATININGA. São Paulo: Departamento do Arquivo do Estado de São Paulo, 46 volumes (1920-).

LEME, P. T de A. P. (1980). Nibiliarquia paulistana histórica e genealógica, $5^{a}$ edição, 3 volumes. Belo Horizonte: Livraria Itatiaia Editora / São Paulo: Editora da Universidade de São Paulo.

LOPEZ, A., MOTA, C. G. (2008). História do Brasil: uma interpretação. São Paulo, Editora Senac São Paulo.

LUÍS, W. (2004). Na Capitania de São Vicente. Brasília: Edições do Senado Federal. Edições eletrônicas.

MADRE DE DEUS, Frei G. da (1975). Memórias para a história da Capitania de São Vicente hoje chamada de São Paulo. Belo Horizonte: Editora Itatiaia Limitada.

MARCÍLIO, M. (2004). A população paulistana ao longo dos 450 anos da Cidade. Em Paula Porta (Org., 2004). História da cidade de São Paulo: a cidade colonial 1554-1822, vol.1. São Paulo: Paz e Terra, pp. 245-265. 
MESGRAVIS, L. (2004). De bandeirante a fazendeiro: aspectos da vida social e econômica em São Paulo colonial. Em Paula Porta (Org., 2004). História da cidade de São Paulo: a cidade colonial 1554-1822, vol.1. São Paulo: Paz e Terra, pp. 115-139.

MONTEIRO, J. M. (1994). Negros da terra. Índios e bandeirantes nas origens de São Paulo. São Paulo:Companhia das Letras.

MONTEIRO, J.M. (2004). Dos campos de Piratininga ao Morro da Saudade: a presença indígena na história de São Paulo. Em Paula Porta (Org., 2004). História da cidade de São Paulo: a cidade colonial 1554-1822, vol.1. São Paulo: Paz e Terra, pp. 21-69.

MORAES DE CASTILHO, C. M. (1998 / 2001). Seria quatrocentista a base do Português Brasileiro? Em: Mattos e Silva (Org., 2001). Para a História do Português Brasileiro, vol. II, Primeiros estudos. São Paulo: Humanitas / Fapesp, tomo 1, pp. 57-90.

MORAES DE CASTILHO, C. M. (2004 a). A diacronia do dequeísmo: o clítico locativo medieval en e o dequeísmo nas orações relativas. Linguística 15 / 16: 123-160, 2003/2004.

MORAES DE CASTILHO, C. M. (2005 a). O Processo de redobramento sintático no português medieval. A formação das perifrases de estar. Campinas: Universidade Estadual de Campinas, tese de doutoramento.

MORAES DE CASTILHO, C. M. (2005 b). As raízes do dequeísmo. Em Lidia Rodríguez Alfano (Org. 2005). Actas del XIV Congreso de la Asociación de Linguística y Filología de América Latina, vol. I, Monterrey, México, cd-rom.

MORAES DE CASTILHO, C. M. (2009a). A linguagem dos inventários e testamentos: lendo nas entrelinhas. Em M.S.C.B. Bassanezi e T R. Botelho (orgs. 2009). Linhas e entrelinhas: as diferentes leituras das atas paroquiais dos setecentos e oitocentos. Belo Horizonte: Fapemig / Veredas e Cenários, pp. 257-272.

MORAES DE CASTILHO, C. M. (2009c). A concordância nos Inventários do séc. XVII. Primeiras investigações. Em: A. T de Capítulo org. 2009. História do Português Paulista. Série Estudos, vol. 1. Campinas: Fapesp / Setor de Publicações do Instituto de Estudos da Linguagem da Unicamp pp. 333-350.

RHEINGANTZ, C. G. (1965D 1967). Primeiras famílias do Rio de Janeiro (séculos XVI e XVII), 2 volumes. Rio de Janeiro: Livraria Brasiliana Editora.

SALVADOR, J. G. (1976). Os cristãos-novos: povoamento e conquista do solo brasileiro, 1530-1680. São Paulo: Pioneira, Ed. da Universidade de São Paulo.

SALVADOR, J. G. (1978). Os cristãos-novos e o comércio no Atlântico Neridional: com enfoque nas capitanias do Sul, 1530-1680. São Paulo: Pioneira.

SAUNDERS, A.C. de C.M. (1982 / 1994). História social dos escravos libertos negros em Portugal (1441-1555). Lisboa: Imprensa Nacional - Casa da Moeda. [original publicado em 1982 pela CUP].

SIMÕES, J. / KEWITZ, V. (2010). Recortes temáticos e mapeamento de Tradições Discursivas no corpus do PHPB. Em D. da Hora e C. Rosa Silva (orgs. 2010). Para a História do Português Brasileiro. Abordagens e perspectivas. João Pessoa: Ideia/Editora Universitária, pp. 21-28.

TAUNAY, A. d' E. (s/d). História das bandeiras paulistas, $2^{\mathrm{a}}$ edição, 3 tomos. São Paulo, Edições Melhoramentos

TAUNAY, A. d’ E. (1921). São Paulo no século XVI. História da vila Piratiningana. Tours: E. Arrault \& Cia.

TAUNAY, A. d' E. (1968). João Ramalho e Santo André da Borda do Campo, $2^{a}$ edição. São Paulo: Empresa Gráfica da Revista dos Tribunais S.A. 
THEODOSO, J., RUIZ, R. (2004). São Paulo, da vila a cidade: a fundação, o poder público e a vida política. Em Paula Porta (Org., 2004). História da cidade de São Panlo: a cidade colonial 15541822, vol.1. São Paulo: Paz e Terra, pp. 69-112.

TOLEDO, R. P. de (2003). A capital da solidão: uma história de São Paulo das origens a 1900. Rio de Janeiro: Objetiva.

VILLALTA, L. C. (1997). O que se fala e o que se lê: língua, instrução e leitura. Em Laura de Mello e Souza (org.1997). História da vida privada no Brasil, vol. 1, Cotidiano e vida privada na América portuguesa. São Paulo: Companhia das Letras, pp. 331-385.

WEHLING, A., WEHLING, M. J. C. de (1994). Formaşão do Brasil colonial. Rio de Janeiro: Nova Fronteira.

WIZNITZER, Arnold (1960/1966). Os Judeus no Brasil Colonial, trad. de Olivia Krahenbuhl. São Paulo: Pioneira.

ZEQUINI, A. (2004). A fundação de São Paulo e os primeiros paulistas: indígenas, europeus e mamelucos. Em A formação do Estado de São Paulo, seus habitantes e os usos da terra, 3 volumes. São Paulo: Imprensa Oficial, pp. 29-49. 